\title{
Melanoma of the Conjunctiva pT3 TNM
} Finding $v 7$

National Cancer Institute

\section{Source}

National Cancer Institute. Melanoma of the Conjunctiva pT3 TNM Finding v7. NCI

Thesaurus. Code C88628.

Melanoma of the conjunctiva with tumor invading the eye, eyelid, nasolacrimal system, sinuses, or orbit. (from AJCC 7th Ed.) 